\title{
Helpful technical notes for intraperitoneal natural orifice transluminal endoscopic surgery (NOTES) salvage in a failed EUS-guided gastroenterostomy scenario
}

The main reasons for dislodgement of the distal flange of a lumen-apposing metal stent (LAMS) into the peritoneum during endoscopic ultrasound (EUS)guided gastroenterostomy are that the delivery catheter pushes away the small bowel without entering it, or else that advancement of a preloaded guidewire tents away the jejunal loop (in both cases, the EUS window is lost).

The main question is: Is the guidewire still in place? If yes, the action of choice is coaxial insertion of a second (coaxial) stent (LAMS, enteral self-expandable metal stent) through the misdeployed LAMS. If not, three options have been reported: LAMS-in-LAMS rescue with -intraperitoneal EUS guidance; natural orifice transluminal endoscopic surgery (NOTES); or surgery.

We offer some helpful technical notes for intraperitoneal NOTES salvage ( $\mathbf{F i g . 1 ,}$

\section{> Fig. 2, > Fig. 3; - Video 1):}

1. Do not remove the transgastric misplaced LAMS! Use it as an internal trocar for intraperitoneal NOTES.

2. Exchange the echoendoscope for a therapeutic gastroscope (single or double-channel). After balloon expansion of the LAMS up to $15 \mathrm{~mm}$, the scope is ready for NOTES through the misplaced LAMS.

3. NOTES: From the stomach, (i) suction a jejunal loop into the distal LAMS flange and access it by cutting with a needle-knife, or (ii) access the peritoneal cavity and incise the bowel wall with a needle-knife. After this, advance a guidewire through the needle-knife and coil it in the jejunum. (If a double-channel scope is used, the jejunal loop can be grasped with a rat-tooth forceps and the needleknife can be advanced through the second channel).

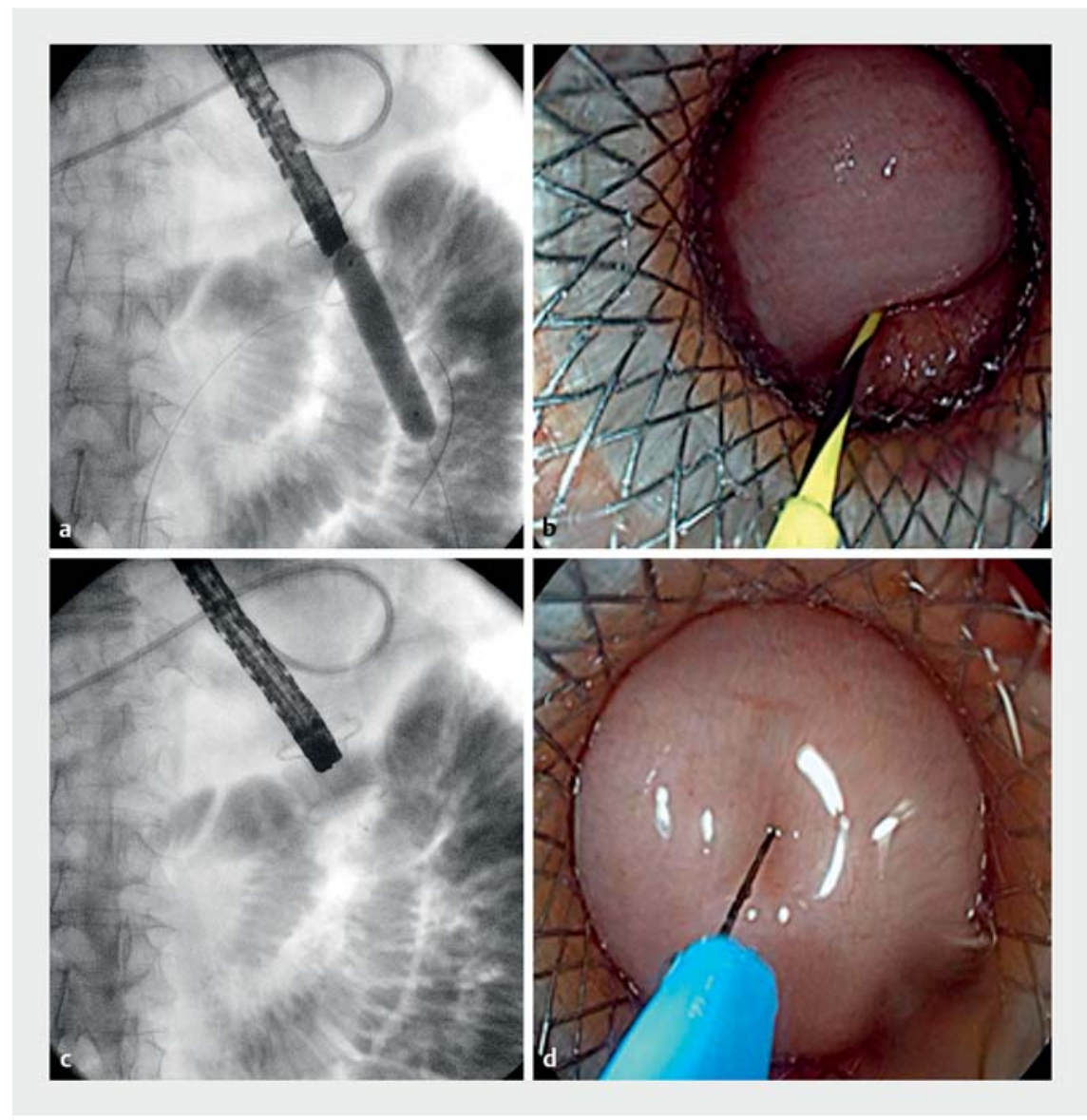

- Fig. 1 a Balloon dilation of a lumen-apposing metal stent (LAMS) to allow scope passage; $\mathbf{b}, \mathbf{c}$ jejunal loop seen through the misplaced LAMS; $\mathbf{d}$ suctioning of small bowel into the transgastric LAMS before cutting with a needle-knife.

4. Under endoscopic/fluoroscopic guidance, deploy a second coaxial rescue stent within the misplaced stent to create a bridge between the small bowel and the stomach. A LAMS-inLAMS option may be preferred, given that the cautery system will help to gain access through the jejunum wall.
Relevant technical aspects during NOTEs are to: limit $\mathrm{CO}_{2}$ insufflation; maneuver carefully; stabilize the guidewire; ensure meticulous fluoroscopic monitoring to help advancement of the second LAMS delivery catheter into the small bowel [1-4].

Endoscopy_UCTN_Code_CPL_1AL_2AB 

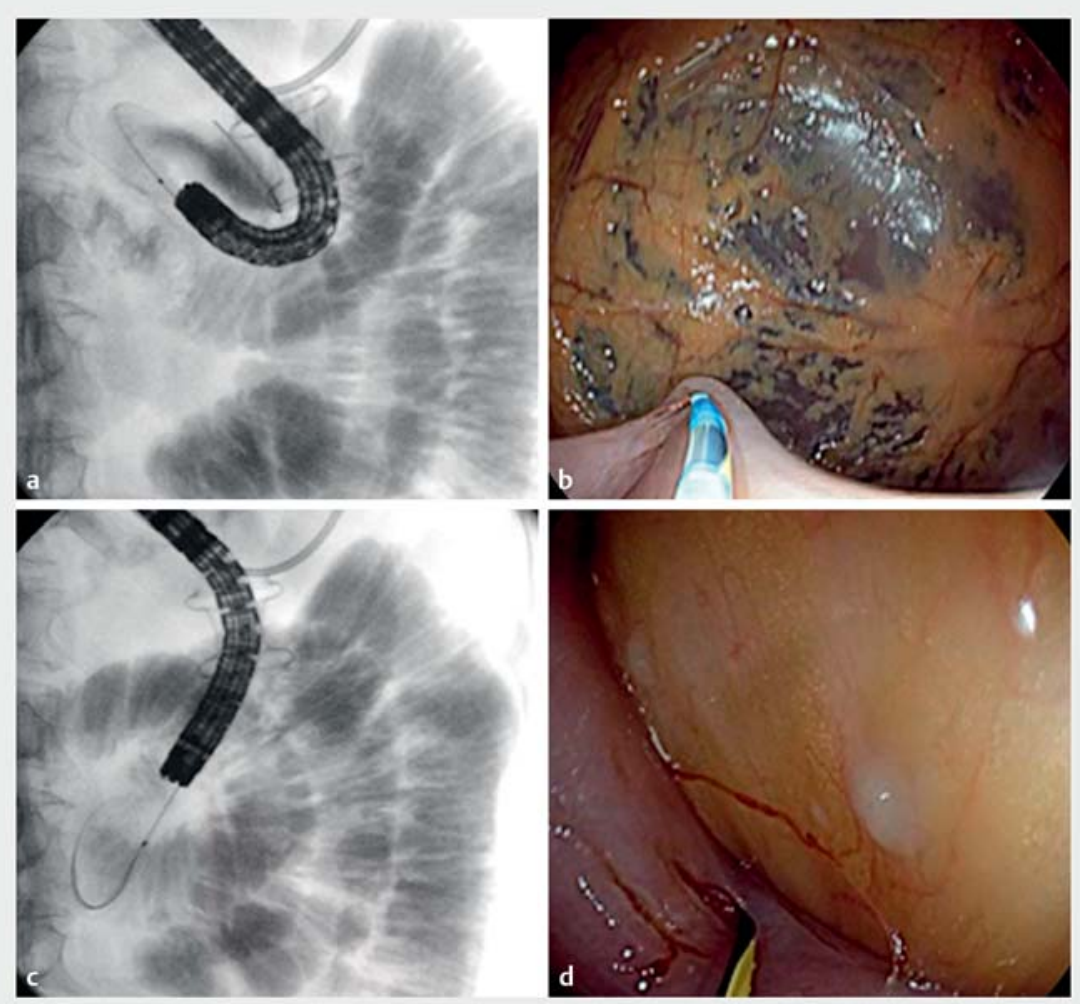

- Fig. 2 a-d Peritoneoscopy: accessing a jejunal loop. a, b Avoid an acute angle like this (the liver is seen). c, $\mathbf{d}$ Try to maintain the LAMS and the scope in the same plane.
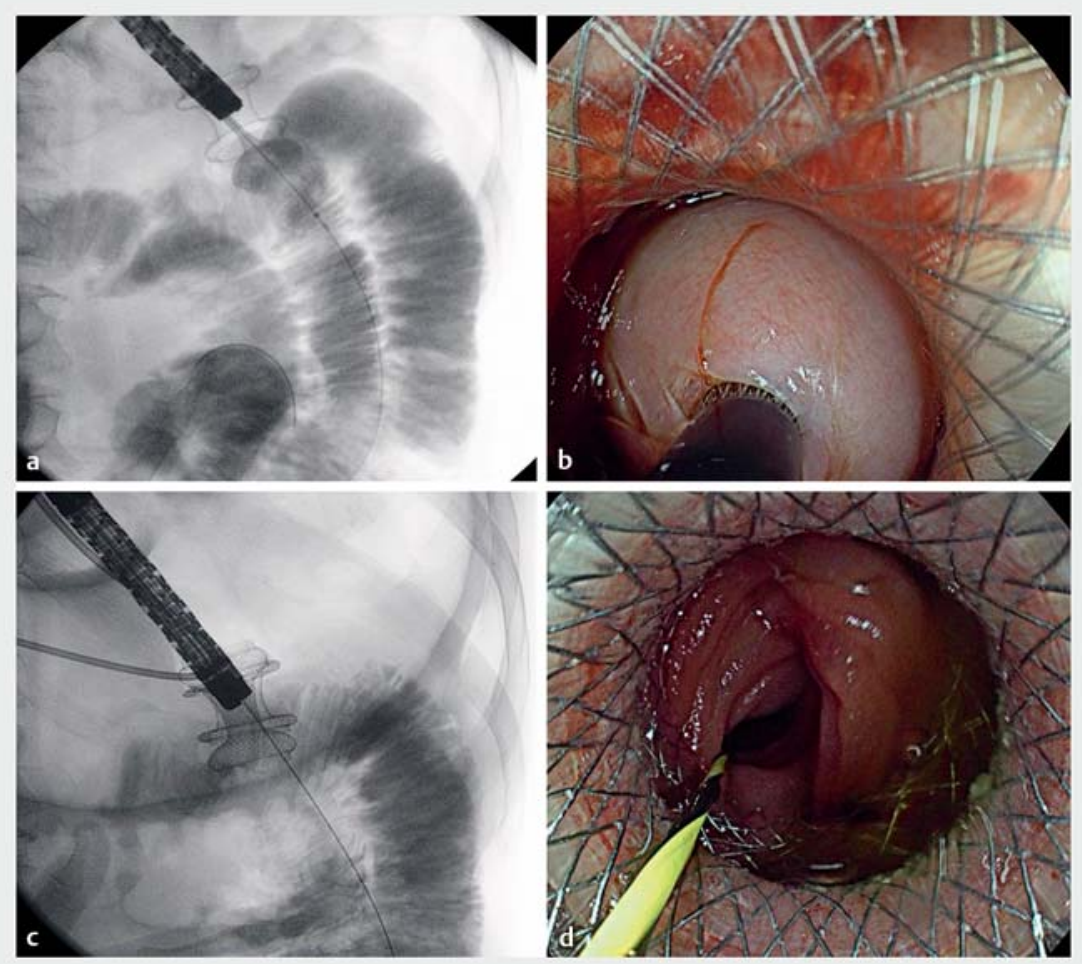

Fig. 3 a, b The second LAMS delivery catheter with its distal flange deployed inside the jejunal loop is pulled into the misplaced LAMS. c, $\mathbf{d}$ The second LAMS in position within the first LAMS, creating a bridge between the small bowel and the stomach.
Competing interests

J. B. Gornals is a consultant for Boston Scientific.

The authors

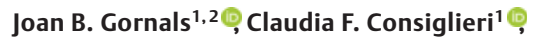
Sandra Maisterra ${ }^{1}$, Albert Garcia-Sumalla ${ }^{1}$, Julio G. Velasquez-Rodriguez ${ }^{1}$, Carme Loras ${ }^{2,3}$

1 Endoscopy Unit, Department of Digestive Diseases, Hospital Universitari de Bellvitge, Bellvitge Biomedical Research Institute (IDIBELL), University of Barcelona, Catalonia, Spain

2 Faculty of Health Sciences, Universitat Oberta de Catalunya, Barcelona, Catalonia, Spain

3 Endoscopy Unit, Department of Digestive Diseases, Hospital Universitari Mutua de Terrassa, Fundacio per la Recerca Mutua de Terrassa, CIBERehd, Terrassa, Catalonia, Spain

Corresponding author

\section{Joan B. Gornals, MD, PhD}

Endoscopy Unit, Department of Digestive Diseases, Hospital Universitari de Bellvitge IDIBELL, Feixa Llarga s/n, 08907 L'Hospitalet de Llobregat, Barcelona, Catalonia, Spain jgornals@bellvitgehospital.cat

\section{References}

[1] Sanchez-Ocana R, Penas-Herrero I, Gil-Simon $P$ et al. Natural orifice transluminal endoscopic surgery salvage of direct EUS-guided gastrojejunostomy. VideoGIE 2017; 2: 346348

[2] Ligresti D, Amata M, Barresi L et al. The lumen-apposing metal stent (LAMS)-in-LAMS technique as an intraprocedural rescue treatment during endoscopic ultrasoundguided gastroenterostomy. Endoscopy 2019; 51: 331-332

[3] James TW, Grimm IS, Baron TH. Intraperitoneal echoendoscopy for rescue of a gastrojejunal anastomosis. VideoGIE 2019; 4: 528 529

[4] Tyberg A, Saumoy M, Kahaleh M. Using NOTES to salvage a misdeployed lumenapposing metal stent during an endoscopic ultrasound-guided gastroenterostomy. Endoscopy 2017; 49: 1007-1008 


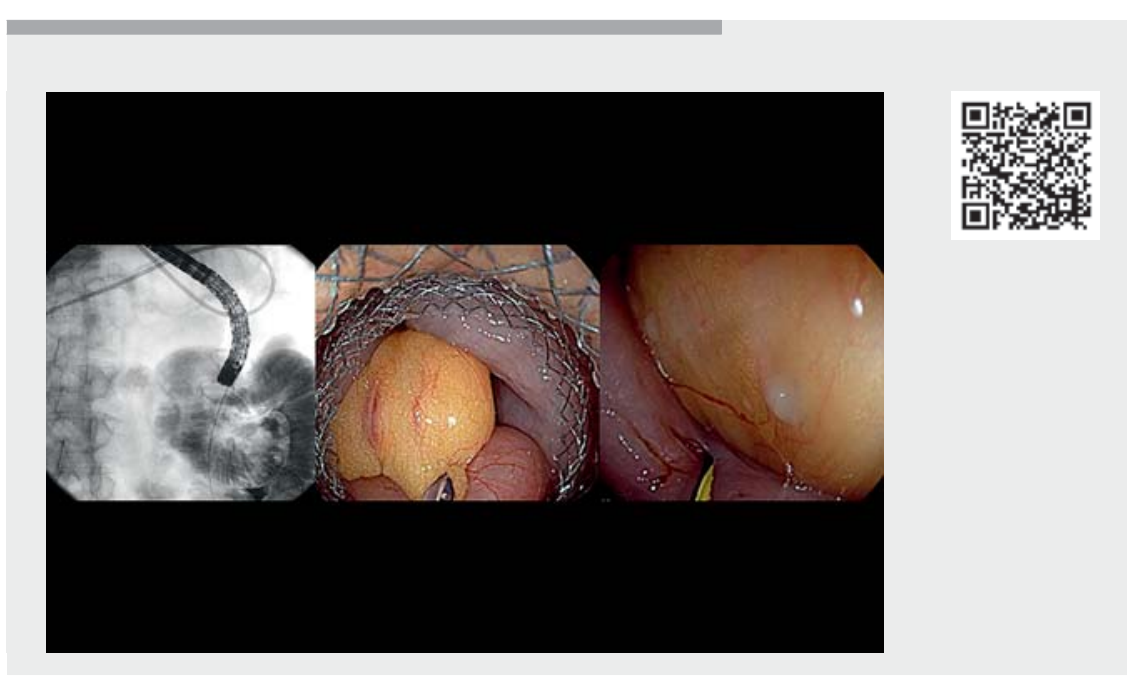

$\checkmark$ Video 1 Helpful technical notes for intraperitoneal natural orifice transluminal endoscopic surgery (NOTES) salvage in the scenario of a failed endoscopic ultrasound-guided gastroenteroanastomy with a misdeployed lumen-apposing metal stent.

\section{Bibliography}

Endoscopy 2022; 54: E287-E289

DOI 10.1055/a-1519-6401

ISSN $0013-726 \mathrm{X}$

published online 2.7.2021

(C) 2021. Thieme. All rights reserved.

Georg Thieme Verlag KG, Rüdigerstraße 14, 70469 Stuttgart, Germany

\section{ENDOSCOPY E-VIDEOS}

https://eref.thieme.de/e-videos

回回 Endoscopy E-Videos is an open access online section, 回证: reporting on interesting cases and new techniques in gastroenterological endoscopy. All papers include a high quality video and all contributions are freely accessible online. Processing charges apply (currently EUR 375), discounts and wavers acc. to HINARI are available.

This section has its own submission website at

https://mc.manuscriptcentral.com/e-videos 